\section{Case Reports in Neurology}

Case Rep Neurol 2020;12:433-439

DOI: 10.1159/000510845

Published online: November 13, 2020

(c) 2020 The Author(s)

Published by S. Karger AG, Basel

www.karger.com/crn

This article is licensed under the Creative Commons Attribution-NonCommercial 4.0 International License (CC BY-NC) (http://www.karger.com/Services/OpenAccessLicense). Usage and distribution for commercial purposes requires written permission.

\title{
Gasperini Syndrome: A Case Report and Systematic Review and Proposing a New Definition
}

\author{
Riwaj Bhagat $^{\mathrm{a}} \quad$ Siddharth Narayanan ${ }^{\mathrm{b}} \quad$ Marwa Elnazeir ${ }^{\mathrm{a}}$ \\ Thong Diep Pham ${ }^{a} \quad$ Robert Paul Friedland ${ }^{a} \quad$ Kerri Remmel $^{a} \quad$ Wei Liu $^{a}$ \\ aDepartment of Neurology, University of Louisville, Louisville, KY, USA; \\ ${ }^{b}$ Department of Surgery, University of Louisville, Louisville, KY, USA
}

\section{Keywords}

Stroke $\cdot$ Cranial nerve $\cdot$ Gasperini syndrome $\cdot$ Brainstem

\begin{abstract}
Gasperini syndrome (GS), a rare brainstem syndrome, is featured by ipsilateral cranial nerves (CN) V-VIII dysfunction with contralateral hemibody hypoesthesia. While there have been 18 reported cases, the GS definition remains ambiguous. We report a new case and reviewed the clinical features of this syndrome from all published reports to propose a new definition. A 57year-old man with acute brainstem stroke had right CN V-VIII and XII palsies, left body hypoesthesia and ataxia. Brain MRI showed an acute stroke in the right caudal pons and bilateral cerebellum. After a systematic review, we classified the clinical manifestations into core and associate features based on the frequencies of occurring neurological deficits. We propose that a definitive GS requires the presence of ipsilateral CN VI and VII palsies, plus one or more of the other three core features (ipsilateral CN V, VIII palsies and contralateral hemibody hemihypalgesia). Additionally, GS, similar to Wallenberg's syndrome, represents a spectrum that can have other associated neurological features. The revised definition presented in this study may enlighten physicians with the immediate recognition of the syndrome and help improve clinical localization of the lesions and its management.




\section{Case Reports in Neurology}

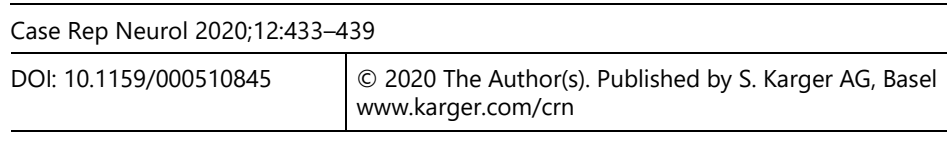

Bhagat et al.: Gasperini Syndrome

\section{Introduction}

Gasperini syndrome (GS) is a rare alternating brainstem syndrome resulting from a lesion in the caudal pontine tegmentum. After its first description in 1912 [1], there have only been 18 reported cases [2-8]. While this syndrome is characterized by ipsilateral peripheral facial palsy, abducens nerve palsy, hypacusis, facial sensory loss, and contralateral hemisensory loss [2-9], its definition is still ambiguous. We present a case of GS caused by an acute brainstem stroke. With a thorough review of reported cases, we propose a new definition of the syndrome based on the frequency of occurring neurological deficits. A GS case must have at least three of the five characteristic features. In addition, GS is a spectrum that may have other associated features.

\section{Case Report}

A 57-year-old male presented with a sudden onset of dysarthria, diplopia, and vertigo. Neurological examination revealed equal pupils, intact pupillary light reflex, impaired right corneal reflex, right abducens palsy, left beating horizontal nystagmus on left gaze, right facial sensory loss to pain, temperature and touch, right entire facial weakness, right hearing loss (HL), tongue deviation to the right, dysarthria, left-side body sensory loss to pain, temperature and touch, bilateral ataxia and intact motor strength of the extremities. He had normal deep tendon reflexes and Babinski's sign was absent. Brain MRI showed an acute stroke in the right caudal pons and bilateral cerebellum (Fig. 1a). Head and neck CT angiography showed thrombus in the proximal basilar artery and bilateral vertebral arteries occlusion at their origin with distal reconstitution. He recovered well after the cerebellar swelling subsided. On the 6-month follow-up, he had complete recovery of right facial, abducens, and hypoglossal palsies. Dysarthria and ataxia improved. The patient still had persistent sensory loss to all modalities on the right-side face and left-side body, as well as right HL.

\section{Discussion}

GS is a brainstem syndrome, currently defined by ipsilateral cranial nerve (CN) V, VI, VII and VIII palsies, and contralateral hemihypalgesia below the neck [4]. The lesion is localized to the caudal pontine tegmentum at the level of the facial colliculi. The pontine tegmentum consists of the nuclei of the trigeminal, abducens, facial and auditory/vestibular nerves and their emerging fibers, lateral lemniscus, lateral spinothalamic tract, and two paramedian structures: median longitudinal fasciculus and medial lemniscus [10] (Fig. 1b).

Millard-Gubler syndrome and Foville syndrome can be confused with GS, as both also have ipsilateral facial palsy with either ipsilateral abducens palsy (Millard-Gubler), or ipsilateral gaze palsy (Foville). However, in contrast to GS, both their lesions extend ventrally toward the basis pontis causing contralateral hemiplegia. Raymond syndrome, localized more ventrally at medial basis pontis, affects ipsilateral abducens nerve and corticospinal tract but spares CN VII $[11,12]$. 


\section{Case Reports in Neurology}

Case Rep Neurol 2020;12:433-439

DOI: $10.1159 / 000510845$

(C) 2020 The Author(s). Published by S. Karger AG, Base www.karger.com/crn

Bhagat et al:: Gasperini Syndrome

There has been ambiguity in defining GS in previously reported cases. One report recognized GS with an ipsilateral CN VII palsy with contralateral hemihypalgesia [2], while another case identified it as ipsilateral CN VI and VII palsies with ataxia [3]. One case included ipsilateral horizontal gaze palsy to define GS [4], but other reports defined this syndrome without CN VI palsies $[7,8]$. Such inconsistencies in characterizing GS indicate that an unequivocal definition of GS is important for prompt recognition of the syndrome and localization of neurological deficits.

The most recent review on GS, published more than a decade ago, summarized presentations of 13 cases with their localizations [4]. To further consolidate key features for better delineation of the syndrome, we reviewed all 18 published cases with their deficits, and categorized the core and associated features based on their overall frequencies. Except for the original case, localizations of the lesions were confirmed by neuroimaging studies. While cases 2-10 (Table 1) were reported in non-English languages, their deficits were tabulated by Hayashi-Hayata et al. [4] in English.

As shown in Table 1, ipsilateral right whole facial palsy was observed in all cases. It localizes to $\mathrm{CN} /$ nucleus VII. The facial nucleus is deeply embedded in the dorsolateral pontine tegmentum and its nerve courses dorsally and loops around the abducens nucleus as facial geniculum forming the facial colliculus, and courses ventrally to exit from the pontomedullary junction $[10,12,13]$. Sixteen cases $(84 \%)$ had ipsilateral abducens palsy, localizing to CN VI nucleus or nerve. The abducens nerve emerges from its nucleus that lies in the facial colliculus and courses ventrally to exit from the pontomedullary junction [10].

Sixteen cases (84\%) had facial hemihypalgesia, 12 of which (63\%) were ipsilateral. Facial sensory loss localizes to the spinal and chief sensory nucleus of the trigeminal nerve [13]. Contralateral facial hemihypalgesia was reported in 3 cases, which localizes to the trigeminothalamic tract and trigeminal lemniscus that carries contralateral sensory information from the spinal nucleus and chief sensory nucleus of trigeminal nerve, respectively [13]. One patient had bilateral facial hemihypalgesia. Sensory nuclei of trigeminal nerve lie lateral to abducens nucleus while the trigeminothalamic tract and trigeminal lemniscus lie dorsolateral to medial lemniscus $[10,12,13]$. There were 14 cases $(74 \%)$ having HL. The original case reported contralateral HL localizing the lesion to the lateral lemniscus $[10,13]$, while in the follow-up examination, 11 cases (58\%) had ipsilateral and 2 cases had bilateral HL. Ipsilateral HL localizes to $\mathrm{CN}$ /nucleus VIII, while bilateral HL localizes to both $\mathrm{CN} /$ nucleus VIII and lateral lemniscus. Contralateral body hemihypalgesia was seen in 16 cases (84\%), suggesting dysfunction of the spinothalamic tract, which lies dorsolateral to the medial lemniscus in the pontine tegmentum [10].

Overall, 10 cases (53\%) had ipsilateral facial palsy, abducens palsy, HL, facial hemihypalgesia, and contralateral body hemihypalgesia. Sixteen out of the 19 cases had at least three or more of the five deficits. Based upon the frequency of deficits, we propose that ipsilateral CN V-VIII palsies, and contralateral body hemihypalgesia are the five GS core features (Fig. 1c). The diagnosis of GS can be established if a patient presents with at least three of these five core features.

GS patients may also have other associated features, as the brainstem is a small area that includes many vital structures. Ipsilateral horizontal conjugate gaze palsy was noted in 3 cases, localizing the lesion either to the paramedian pontine reticular formation or the abducens nucleus. They were all accompanied with ipsilateral abducens palsy, suggesting that the 


\section{Case Reports in Neurology}

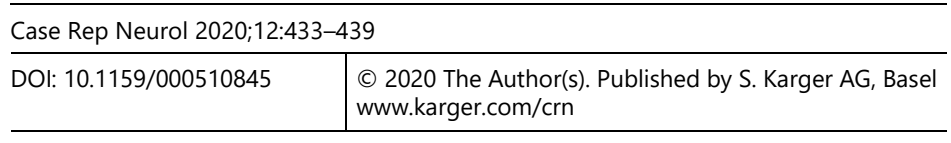

Bhagat et al.: Gasperini Syndrome

lesion was in the abducens nucleus not the paramedian pontine reticular formation. Seven cases had ataxia, which suggests involvement of either the middle cerebellar peduncle or cerebellum $[10,12,13]$. Six reported cases had ipsilateral ataxia. Our patient had bilateral ataxia as he had co-existing bilateral cerebellar strokes. Body weakness is usually not a cardinal feature. Contralateral hemiparesis was only reported in the original case and case 17 , which localized to the ipsilateral corticospinal tract $[10,12,13]$. Our patient, along with the original case, had ipsilateral tongue deviation, which demonstrates hypoglossal nerve or nuclei involvement. Thus, we propose that GS, like the Wallenberg syndrome [12], is a spectrum with a constellation of neurological symptoms.

GS is most commonly caused by occlusion of the anterior inferior cerebellar artery, or, less commonly, of a pontine penetrating branch of the basilar artery [9]. Occlusion of the anterior inferior cerebellar artery can cause a lateral inferior pontine syndrome (LIPS), which has ipsilateral facial palsy, diminished facial sensation, gaze palsy, ipsilateral deafness, ataxia, and contralateral hemihypalgesia [12]. LIPS and GS share many clinical features as both could have the same major arterial occlusion. However, GS differs from LIPS in having abducens nerve palsy with and without conjugate gaze palsy instead of conjugate gaze palsy without abducens palsy as seen in LIPS.

Occlusion of a paramedian branch of the basilar artery leads to the medial inferior pontine syndrome, which includes ipsilateral abducens and gaze palsy, ataxia and contralateral body tactile and proprioception loss and weakness without involvement of ipsilateral peripheral facial palsy and facial hemihypalgesia [12]. Therefore, a definitive GS not only has at least three of the five core features, but also co-existing CN VI and VII palsies. Applebaum and Ferguson [14] reported a case having ipsilateral CN V-VIII palsies with ipsilateral hand and foot numbness. Based on our revised definition, this patient could also be classified as having GS instead of an ambiguous latero-medial inferior pontine syndrome. GS was less frequently reported in pontine hemorrhage [1, 4] and multiple sclerosis [5].

In conclusion, GS is a distinct rare crossed brainstem syndrome localized to the caudal pontine tegmentum. Based on the frequencies of neurological deficits, we redefine GS by the presence of ipsilateral CN VI and VII palsies, plus one or more of the other three core features (ipsilateral CN V, VIII palsies and contralateral hemihypalgesia). Among the five core features, co-existence of the facial palsy and abducens palsy distinguishes GS from LIPS. GS may also present with other neurological deficits, such as conjugate gaze palsy, tongue deviation, ataxia, contralateral facial hemihypalgesia, HL and hemiparesis. Therefore, GS, similar to the more common Wallenberg syndrome, is a spectrum with a constellation of neurological symptoms. We hope the revised GS definition leads to more cases being readily recognized and improves the clinical localization of the lesions and treatment.

\section{Acknowledgement}

We acknowledge our patient for giving permission to report his clinical data. 


\section{Case Reports in Neurology}

\section{Statement of Ethics}

The patient described in this paper has given written, informed consent to publish his case and radiographic images. The study is waived by the institutional review board of the University of Louisville.

\section{Conflict of Interest Statement}

The authors report no conflicts of interest.

\section{Funding Sources}

This research did not receive any specific grant from funding agencies in the public, commercial, or not-for-profit sector.

\section{Author Contributions}

R.B. and W.L. were major contributors in conception, acquisition of data and interpretation. S.N., M.E., T.D.P., R.P.F. and K.R. read and approved the final manuscript.

\section{References}

1 Gasperini U. Di un caso di emorragia protuberanziale. Contributo clinico allo studio delle sindromi pontine inferiori. Rif Med (Napoli). 1912;28:880-98.

2 Schwaninger M, Kanemoto K, Kölmel HW. [Gasperini syndrome - differential diagnosis of peripheral facial nerve paralysis. Neurologic and imaging findings]. HNO. 1993 Nov;41(11):536-8.

3 Roquer J, Lorenzo JL, Pou A. The anterior inferior cerebellar artery infarcts: a clinical-magnetic resonance imaging study. Acta Neurol Scand. 1998 Apr;97(4):225-30.

4 Hayashi-Hayata M, Nakayasu H, Doi M, Fukada Y, Murakami T, Nakashima K. Gasperini syndrome, a report of two cases. Intern Med. 2007;46(3):129-33.

5 Krasnianski M, Müller T, Zierz S, Winterholler M. Gasperini syndrome as clinical manifestation of pontine demyelination. Eur J Med Res. 2009 Sep;14(9):413-4.

6 Vesza Z, Várallyay G, Szoke K, Bozsik G, Manhalter N, Bereczki D, et al. Trigemino-autonomic headache related to Gasperini syndrome. J Headache Pain. 2010 Dec;11(6):535-8.

7 Ogawa K, Suzuki Y, Takahashi K, Akimoto T, Kamei S, Soma M. Clinical Study of Seven Patients with Infarction in Territories of the Anterior Inferior Cerebellar Artery. J Stroke Cerebrovasc Dis. 2017 Mar;26(3):574-81.

8 Iorio R. Teaching NeuroImages: gasperini syndrome. Neurology. 2018 Jan;90(3):e261.

9 Tacik P, Alfieri A, Kornhuber M, Dressler D. Gasperini's syndrome: its neuroanatomical basis now and then. J Hist Neurosci. 2012 Jan;21(1):17-30.

10 Mancall EL, Brock DG, Gray H. Gray's clinical neuroanatomy: the anatomic basis for clinical neuroscience. Elsevier/Saunders; 2011.

11 Satake M, Kira J, Yamada T, Kobayashi T. Raymond syndrome (alternating abducent hemiplegia) caused by a small haematoma at the medial pontomedullary junction. J Neurol Neurosurg Psychiatry. 1995 Feb;58(2):261.

12 Brazis PW, Masdeu JC, Biller J. Localization in clinical neurology. Lippincott Williams \& Wilkins; 2012.

13 Blumenfeld H. Neuroanatomy through clinical cases. 2nd ed. Sunderland (Mass.): Sinauer Associates; 2010.

14 Applebaum EL, Ferguson RJ. The latero-medial inferior pontine syndrome. Ann Otol Rhinol Laryngol. 1975;84(3):379-83. 


\section{Case Reports in Neurology}

a
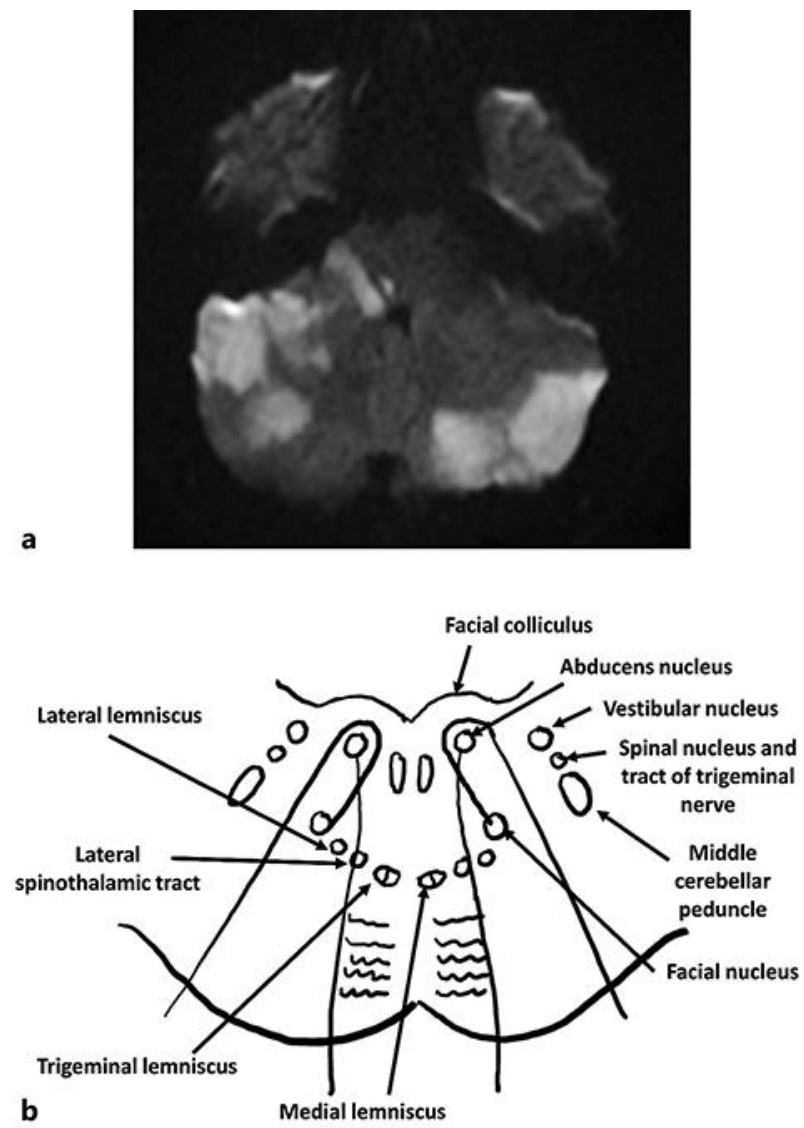

b

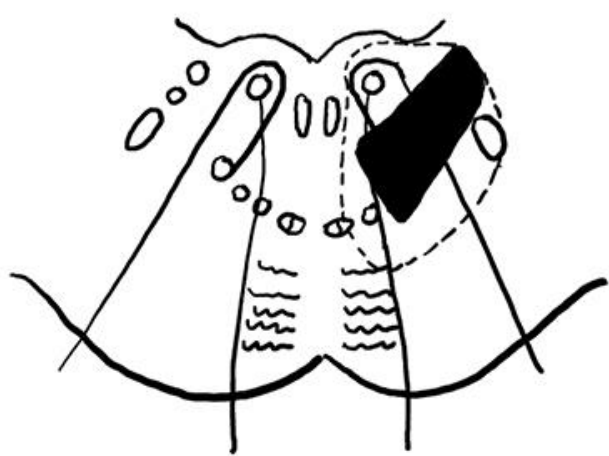

Fig. 1. Gasperini syndrome (GS) imaging in our patient and a schema of the pons and the lesions. a Brain MRI diffusion-weighted imaging showed diffusion restriction changes in the right caudal pons and bilateral cerebellum. b Schematic representation of a transverse section of lower pons. c Schema of lesion (black shade) causing core neurological deficits and lesion (area within dotted line) including associated features of GS. 
Case Reports in

Neurology
Case Rep Neurol 2020;12:433-439

DOI: $10.1159 / 000510845$

(c)

(C) 2020 The Author(s). Published by S. Karger AG, Basel www.karger.com/crn

Bhagat et al.: Gasperini Syndrome

Table 1. Summary of the clinical features of all GS cases

\begin{tabular}{|c|c|c|c|c|c|c|c|c|c|c|}
\hline \multirow[t]{2}{*}{ Case/age/sex } & \multicolumn{5}{|c|}{ Core features } & \multicolumn{4}{|c|}{ Associated features } & \multirow[t]{2}{*}{ Authors } \\
\hline & FP & $\mathrm{FH}$ & $\mathrm{AP}$ & HL & $\mathrm{HH}$ & $\mathrm{AX}$ & CGP & HP & $\mathrm{TD}$ & \\
\hline $1 / 49 / F$ & I & $\mathrm{C}$ & I & $\mathrm{C}$ & $\mathrm{C}$ & & I & $\mathrm{C}$ & I & Gasperini [1] \\
\hline $2 / 49 / \mathrm{M}$ & I & & I & I & $\mathrm{C}$ & I & & & & $\begin{array}{l}\text { Hayashi-Hayata et al. } \\
\text { [4] }\end{array}$ \\
\hline $3 / 27 / \mathrm{F}$ & I & I & I & BL & $\mathrm{C}$ & & & & & $\begin{array}{l}\text { Hayashi-Hayata et al. } \\
\text { [4] }\end{array}$ \\
\hline $4 / 49 / F$ & I & I & I & I & $\mathrm{C}$ & & & & & $\begin{array}{l}\text { Hayashi-Hayata et al. } \\
\text { [4] }\end{array}$ \\
\hline $5 / 75 / \mathrm{F}$ & I & & & & C & & & & & $\begin{array}{l}\text { Schwaninger et al. } \\
\text { [2] }\end{array}$ \\
\hline $6 / 42 / \mathrm{F}$ & I & I & I & I & $\mathrm{C}$ & I & & & & $\begin{array}{l}\text { Hayashi-Hayata et al. } \\
\text { [4] }\end{array}$ \\
\hline $7 / 70 / M$ & I & I & I & I & $\mathrm{C}$ & I & & & & $\begin{array}{l}\text { Hayashi-Hayata et al. } \\
{[4]}\end{array}$ \\
\hline $8 / 42 / \mathrm{M}$ & I & $\mathrm{BL}$ & I & $\mathrm{BL}$ & $\mathrm{C}$ & I & I & & & $\begin{array}{l}\text { Hayashi-Hayata et al. } \\
\text { [4] }\end{array}$ \\
\hline $9 / 62 / \mathrm{F}$ & I & I & I & I & $\mathrm{C}$ & & & & & $\begin{array}{l}\text { Hayashi-Hayata et al. } \\
\text { [4] }\end{array}$ \\
\hline $10 / 68 / \mathrm{F}$ & I & I & I & I & $\mathrm{C}$ & & & & & $\begin{array}{l}\text { Hayashi-Hayata et al. } \\
\text { [4] }\end{array}$ \\
\hline $11 / 58 / \mathrm{F}$ & I & & I & & & I & & & & Roquer et al. [3] \\
\hline $12 / 62 / \mathrm{M}$ & I & $\mathrm{C}$ & I & & $\mathrm{C}$ & & I & & & $\begin{array}{l}\text { Hayashi-Hayata et al. } \\
{[4]}\end{array}$ \\
\hline $13 / 51 / \mathrm{M}$ & I & I & I & & & & & & & $\begin{array}{l}\text { Hayashi-Hayata et al. } \\
\text { [4] }\end{array}$ \\
\hline $14 / 44 / \mathrm{M}$ & I & I & I & I & $\mathrm{C}$ & & & & & Krasnianski et al. [5] \\
\hline $15 / 77 / \mathrm{M}$ & I & I & I & I & & I & & & & Vesza et al. [6] \\
\hline $16 / 62 / \mathrm{W}$ & I & $\mathrm{C}$ & & & $\mathrm{C}$ & & & & & Iorio [8] \\
\hline $17 / 32 / \mathrm{M}$ & I & I & & I & $\mathrm{C}$ & & & $\mathrm{C}$ & & Ogawa et al. [7] \\
\hline $18 / 47 / \mathrm{M}$ & I & I & I & I & $\mathrm{C}$ & & & & & Ogawa et al. [7] \\
\hline 19/57/M & I & I & I & I & $\mathrm{C}$ & BL & & & I & Our case \\
\hline
\end{tabular}

FP, facial palsy; FH, facial hemihypalgesia; AP, abducens palsy; HL, hearing loss; HH, hemihypalgesia; AX, ataxia; CGP, conjugate gaze palsy; HP, hemiparesis; TD, tongue deviation; I, ipsilateral; $\mathrm{C}$, contralateral; $\mathrm{BL}$, bilateral; Blank, absent/not reported. 